\title{
MP-9S Industrial Manipulator Handling and Scrapping Tasks in Industrial Environments
}

\author{
Roland Osszián JÓZSA, ${ }^{1}$ Timotei István ERDEI, ${ }^{2}$ Tibor Péter KAPUSI, ${ }^{3}$ Szabolcs TÓTH, ${ }^{4}$ \\ Géza HUSI ${ }^{5}$ \\ University of Debrecen, Faculty of Engineering, Debrecen, Hungary \\ 1 immortalskeleton01@gmail.com \\ 2timoteierdei@eng.unideb.hu \\ ${ }^{3}$ kapu-si.tibor@zimbra.inf.unideb.hu \\ ${ }^{4}$ szabolcs978@gmail.com \\ ${ }^{5}$ husigeza@eng.unideb.hu
}

\begin{abstract}
The main goal of the project was to carry out a handling task using a color sensor and thermal sensor, as well as an industrial robotic unit. The selection by color made it possible to represent the sub-process of the production of a sample, where each color can be matched to the corresponding or rejected product. The function of the thermal sensor is to show the delay function for the pro-cess, which occurs when the product does not reach a point in the process at the wrong tempera-ture and needs cooling between the two workflows. The thermal sensor and color sensor were pro-grammed using the ATmega microprocessor, while the manipulator was controlled with industrial PLC. The completed project will serve educational purposes in training for students.
\end{abstract}

Keywords: RTT, industrial manipulator, handling, colour sensor, heat sensor, PLC, ATmega328P, MP-9S.

\section{Introduction}

Handling tasks have become part of our daily lives thus, it is worthwhile to deal with errors that occur during mass production. Since the representation of the task is complex, the problem had to be implemented in an industrial environment, for which the Cyber-Physical \& Intelligent Robot Systems Laboratory lab provided us with a basis in the Department of Mechatronics of the University of Debrecen, Faculty of Technology [1]

\section{Choosing a suitable technology}

During the project an industry robotic unit, PLC and Atmega microcontroller as well as a color and thermal sensor were involved to develop a sorting and fault-debugging system for educational purposes. The MP-9S manipulator, which is the main part of the task, was originally used in automotive factories [2]. The MP-9S was renovated and made possible in line with Industry
4.0 requirements, including PLC and microcontroller-based control, as well as HMI for network control [3].

\section{MP-9S manipulator}

The MP-9S manipulator (Figure 1) pneumatic and has 3 degrees of freedom. The front part of the metal housing has a handle that provides the move-

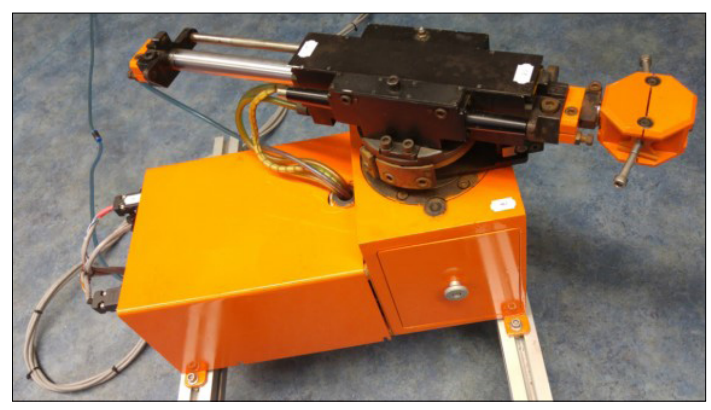

Figure 1. The MP-9S manipulator. 

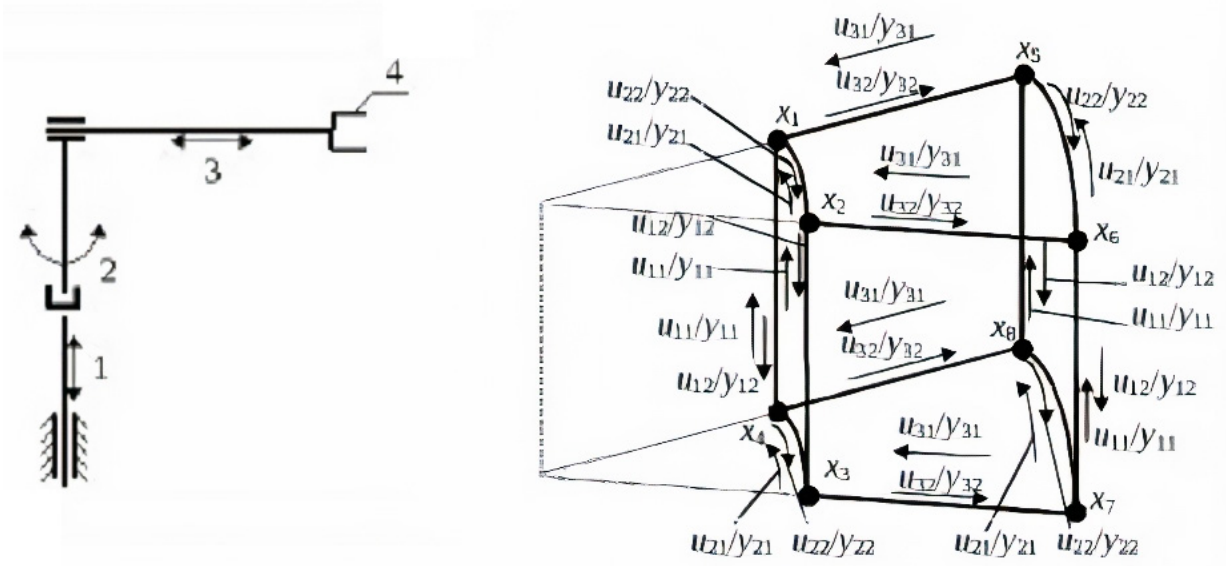

Figure 2. Kinematic chain and manipulator work area. [5]

ment of the gripper head. In the rear, there are 8 electro pneumatic valves with 2 connectors that collect the wires.

The MP-9S robot's kinematic chain (shown in Figure 2) clearly represents a three-axis RTT machine unit. All axes are operated with pneumatic auxiliary energy.

\section{Used sensors and their programming}

\subsection{TCS230-M Colour sensor module}

The TCS230 sensor is used to measure the colour of the area illuminated by the 4 white LEDs (Figure 3). The light sensor can measure RGBW colours, which it converts into frequencies.

Arduino NANO has been used for the control. Arduino is an open source development platform that is part of the ATmega microcontroller family [4]. The main part of Arduino NANO is the ATmega328P microcontroller, which is 8-bit and RISC based (Table 1).

The first step of the program written for the sensor (detail in Figure 4) is to declare the foot allocation and then the pins running into the PLC. Then variables containing the frequency of the colours were declared.

\subsection{MLX90615 Infrared Thermal Sensor}

The thermal sensor is replaced by the INFRARED temperature sensor MLX90614 (Figure 5). It has dimensions of $10,5 \times 13 \times 9,6 \mathrm{~mm}$. Its data are shown in Tabel 2.

The previously written colour detection program (Figure 6) has been added in order to be

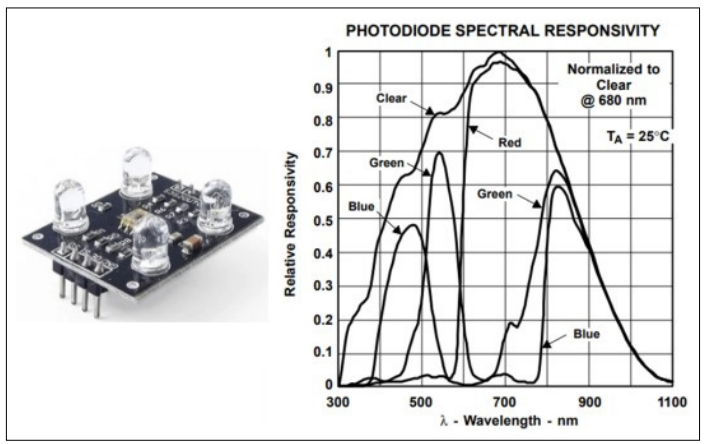

Figure 3. TCS230-M Color sensor module. [6, 7]

Table 1. ATmega328P chip characteristics. [4]

\begin{tabular}{|l|c|}
\hline Program memory type & Flash \\
\hline Program memory & $32 \mathrm{~KB}$ \\
\hline CPU speed & $20 \mathrm{MIPS}$ \\
\hline Digital PWM pins & $6 \mathrm{PWM}$ \\
\hline Temperature range & $-40+85^{\circ} \mathrm{C}$ \\
\hline Operating range & $1.8-5.5 \mathrm{~V}$ \\
\hline Number of legs & 32 \\
\hline
\end{tabular}

Table 2. MLX90615 thermal sensor data. [8]

\begin{tabular}{|l|l|c|}
\hline $\begin{array}{c}\text { Temperature } \\
{\left[{ }^{\circ} \mathbf{C}\right]}\end{array}$ & \begin{tabular}{l} 
Temperature of device \\
\cline { 2 - 3 }
\end{tabular} & $\begin{array}{l}-40+85 \\
\text { Object temperature to }\end{array}$ \\
\hline Measure & $-40+115$ \\
\hline Readurement standard deviation $\left[{ }^{\circ} \mathbf{C}\right]$ & $0.5(0+50)$ \\
\hline Operating voltage range [V] & 0.02 \\
\hline
\end{tabular}




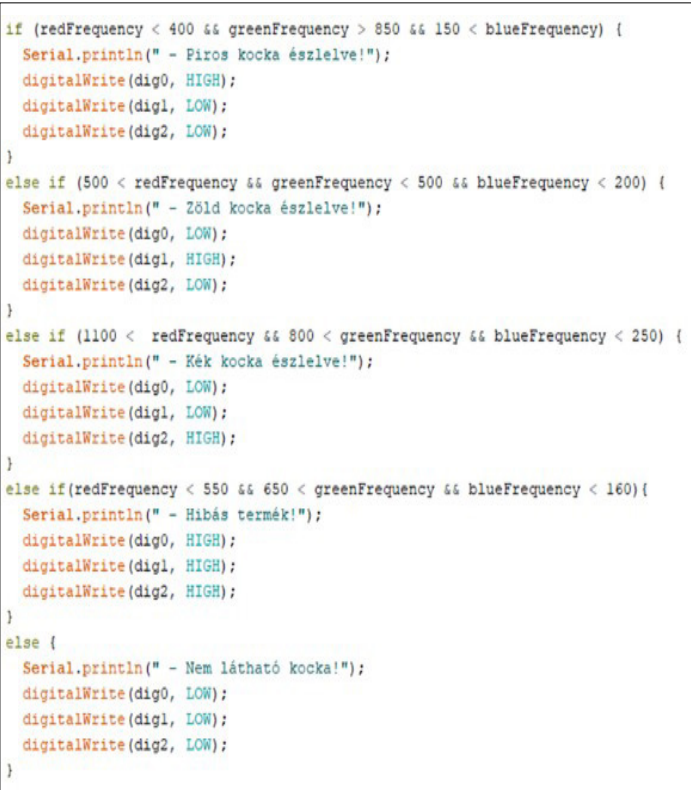

Figure 4. Program snippet: Comparing frequencies.

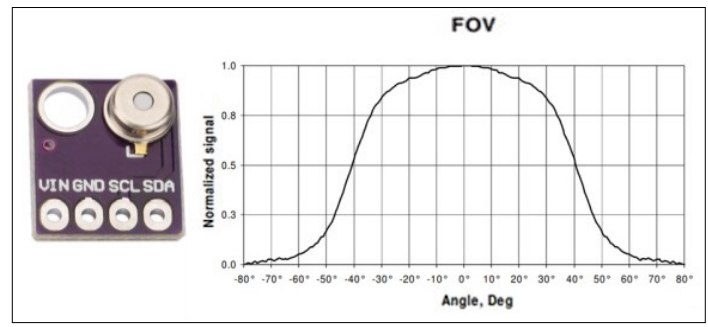

Figure 5. MLX90615 infra heat sensor \& Field of view values. [8]

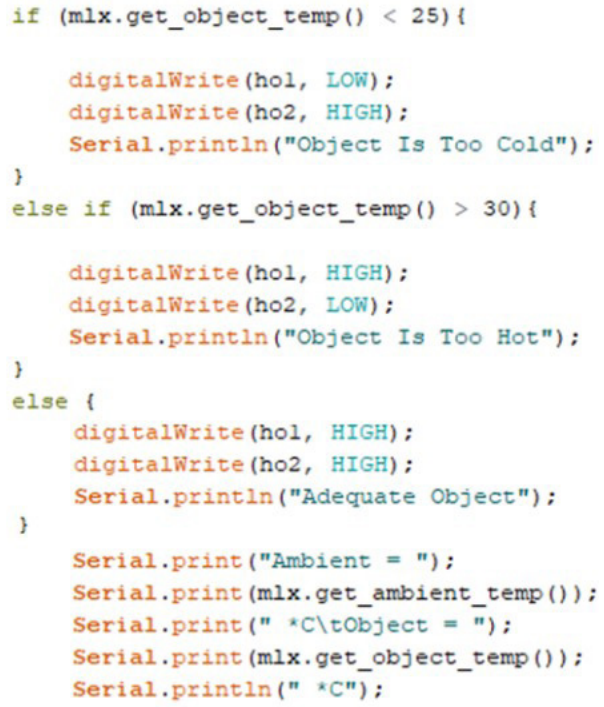

Figure 6. Heat sensor program detail. able to use the MLX90615 thermal sensor. In the first step, the finished file itself was scanned and pins running into the PLC were declared, and the outputs were eventually named.

\subsection{PLC \& ATmega328P sensor wiring dia- gram}

The circuit wiring diagram is shown in Figure 7.

\section{Cube Holder}

The detection distance of the colour sensor is up to $10 \mathrm{~mm}$, so it was necessary to manufacture a cube holder that surrounds the sensor (Figure 8).

\section{MP-9S Control with Industrial Modi- con M340 PLC-vel}

The robotic unit is controlled using a Schneider Modicon M340 modular PLC [9]. The PLC program was written in an LD, or ladder diagram (Figure 9) for the MP-9S, for which the Unity Pro $\mathrm{XL}$ development environment was used.

\section{Conclusions}

The above objectives have been achieved. The MP-9S industrial robot unit is capable of distin-

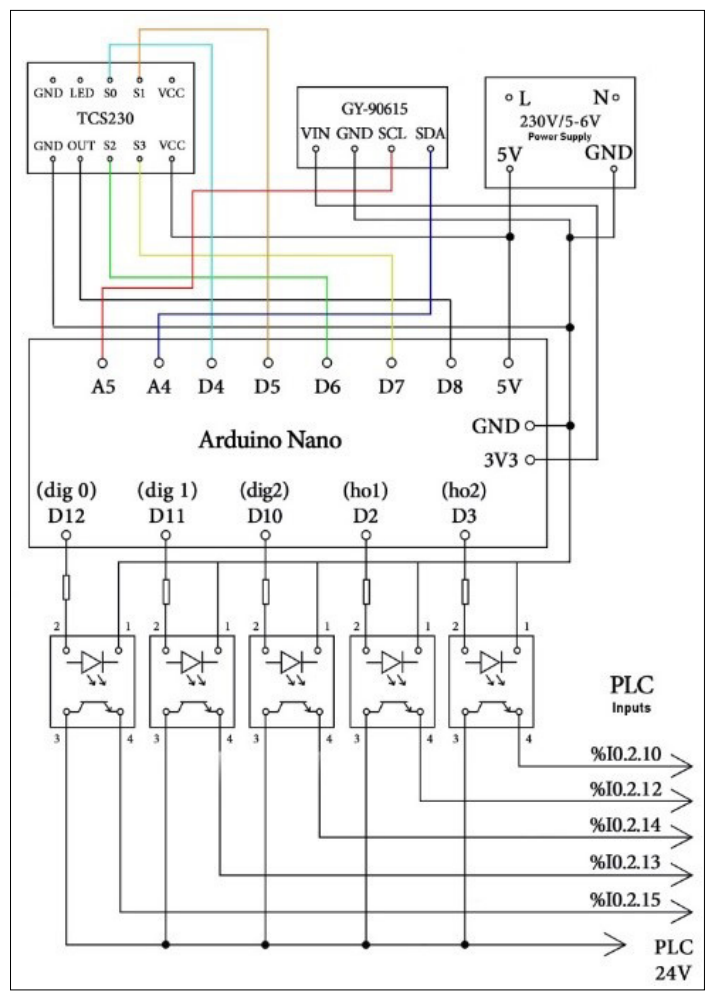

Figure 7. Wiring diagram. 

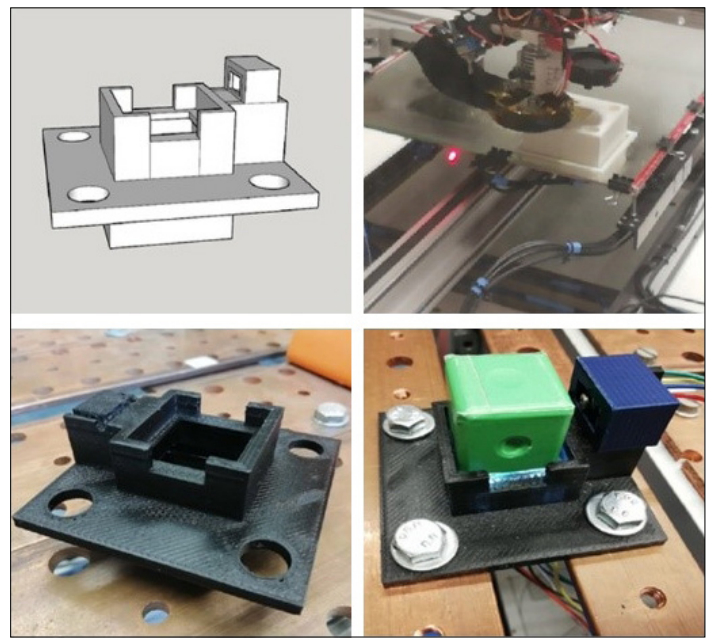

Figure 8. Cube Holder model and $3 D$ printing.

guishing and sorting specific elements by using heat and colour sensors, according to whether or not the workpiece represented by the cube is defective.

\section{Acknowledgments}

Thank you to all those who participated in the project, especially Péter Horváth Patrik and the Department of Mechatronics of the University of Debrecen, Faculty of Technology. The work/publication is supported by the EFOP-3.6.1-16-2016-00022 project. The project is co-financed by the European Union and the European Social Fund.

\section{References}

[1] Husi G.: Introduction to Robot Technology. (TÁMOP-4.1.2.D-12/1/KONV-2012-0008) 2014.

[2] Popov A. K. A. : Az MP-9SZ ipari robot felépitése és programozása. Moszkva, 2005.

[3] Horváth P. P. , Erdei T. I., Husi G.: Restoration and PLC Control of a Material handling MP-9S Industrial Manipulator Platform. Annals of The Oradea University. Fascicle of Management and Technological Engineering, XXIX (XIX), 2019/2(2) https://doi.org/10.15660/AUOFMTE.2019-2.3453

[4] Arduino NANO PCB. (accessed on: 01.11.2019) https://www.arduino.cc/en/uploads/Main/ArduinoNanoManual23.pdf

[5] V. Novgorod: MP-9S ipari robot programozása. 2005.

[6] TCS230 Datasheet. (accessed on: 01.10.2019) https://www.alldatasheet.com/datasheetpdf/ pdf/202765/TAOS/TCS230.html

[7] Hestore - TCS230-M Single-Supply Operation. (accessed on: 01.11.2019)

https://www.hestore.hu/prod_getfile.php?id=8628

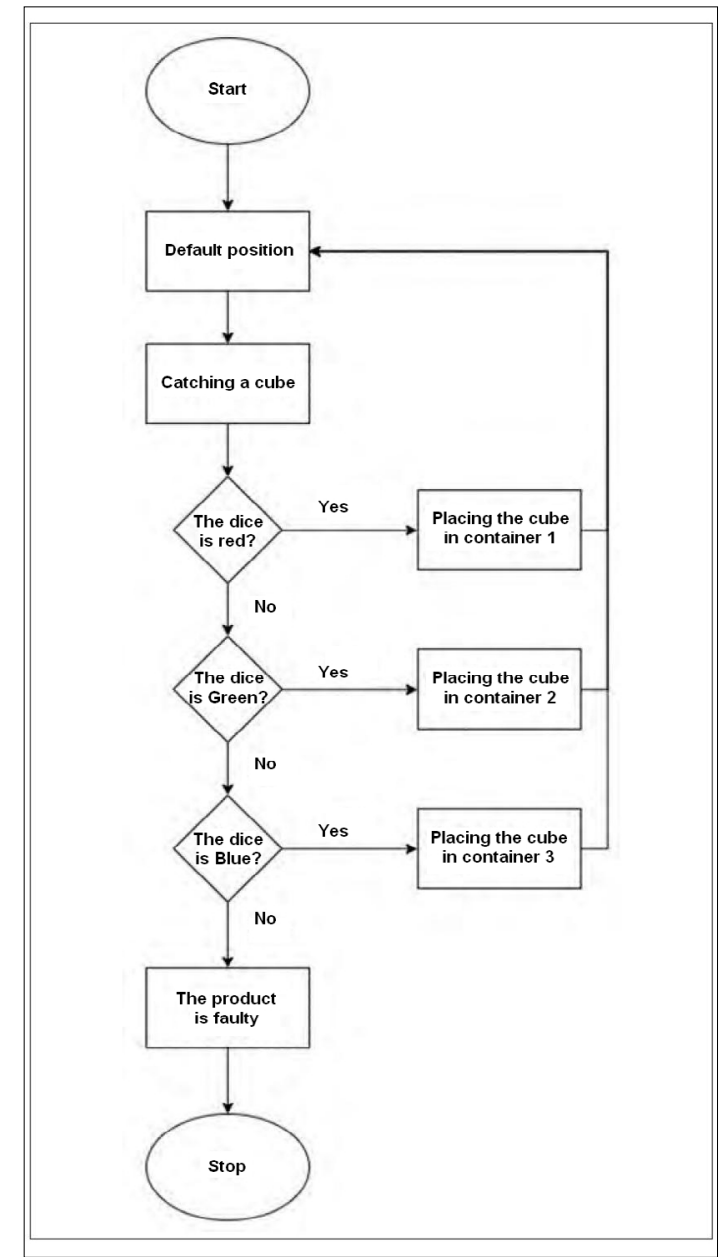

Figure 9. Flowchart of the PLC programme.

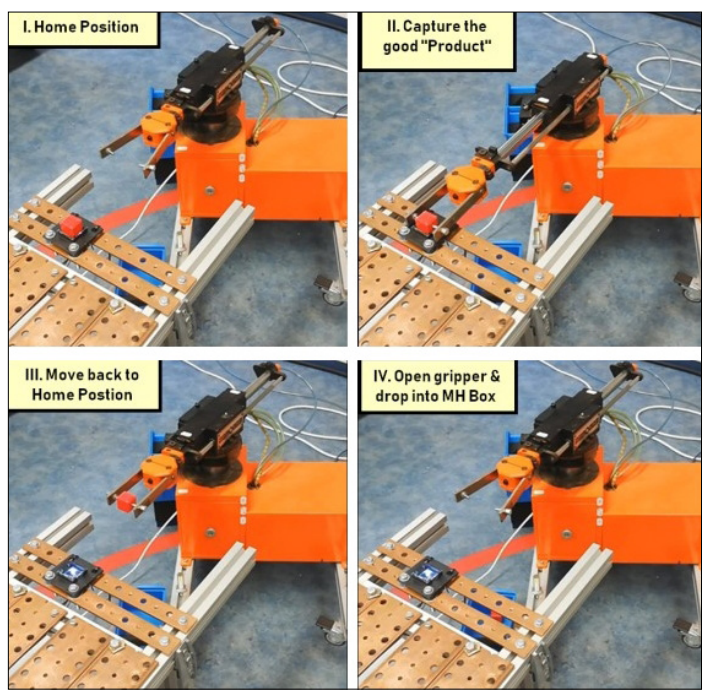

Figure 10. The MP-9S manipulator in action. 
[8] MLX90615-Datasheet-Melexis, (accessed on: 01. 11. 2020)

https://www.melexis.com//media/files/documents/ datasheets/mlx90615-datasheet-melexis.pdf

[9] Schinder Modicon M340. (accessed on: 01.11. 2020) https://www.se.com/hu/hu/product-range-presentation/1468-modicon-m340/\#tabs-top

[10] TCS230-M color light-to-frequency converter. (accessed on: 01.10.2019)

https://www.alldatasheet.com/datasheet-pdf/ pdf/96471/ETC/TCS230D.html

[11] Industrial PLC Programming. (accessed on: 01. 11. 2019). http://zeus.nyf.hu/ elat/PLC-k.pdf
[12] MLX90614 Non-Contact IR Temperature Sen-sor, (accessed on: 01.11.2019)

https://components101.com/sensors/melex-

is-mlx90614-contact-less-ir-temperature-sensor

[13] Erdei T. I., Husi G.: Singularity Measurement in the Cyber-Physical and Intelligent Robot Systems Laboratory. International Review of Applied Sciences and Engineering, 11/2. (2020) 82-87. https://doi.org/10.1556/1848.2020.20001

[14] Google SketchUP, (accessed on: 01. 11. 2020) https://www.sketchup.com/ 